\title{
Epistemology as Engineering?
}

(Forthcoming in Theoria, Vol. 72, Part 1, 2006)

\begin{abstract}
According to a common objection to epistemological naturalism, no empirical, scientific theory of knowledge can be normative in the way epistemological theories need to be. In response, such naturalists as W. V. Quine have claimed naturalized epistemology can be normative by emulating engineering disciplines and addressing the relations of causal efficacy between our cognitive means and ends. This paper evaluates that "engineering reply" and finds it a mixed success. Based on consideration of what it might mean to call a theory "normative," seven versions of the normativity objection to epistemological naturalism are formulated. The engineering reply alone is sufficient to answer only the four least sophisticated versions. To answer the others, naturalists must draw on more resources than their engineering reply alone provides.
\end{abstract}

\section{Introduction}

Knowledge requires justified belief, and justified belief requires the "correct" or "good" use of one's cognitive resources. To understand knowledge, then, we need to understand this sort of goodness. So, claims Jaegwon Kim, "Epistemology is a normative discipline as much as, and in the same sense as, normative ethics" (2000, p. 302).

Explaining how a scientific theory could do epistemology's normative work has been the perennial problem for epistemological naturalism. Naturalists think science will provide the best understanding of knowledge's nature, but science seems ill-suited to go 
beyond the empirical description of how we do manage our belief and tell us what it means to manage our beliefs properly. The problem, apparently, is that scientific theories about knowledge might be within our grasp, but a scientific theory of knowledge might be a conceptual impossibility.

That is the "normativity objection" to epistemological naturalism. I evaluate a standard response to the objection in this paper. W. V. Quine has suggested that "normative epistemology" is best seen as an engineering discipline, concerned with questions about how best to suit our cognitive means to our cognitive ends (1998, pp. 664-5). Its normativity is thus the instrumental normativity of means and ends. This "engineering reply" can be hard to evaluate, though, because it has rarely been worked out in much detail. Here, therefore, I set out both the normativity objection and the engineering reply in more detail than usual, so their respective strengths and weaknesses can be compared. The engineering reply, I conclude, sufficiently answers only the least sophisticated versions of the normativity objection; it is insufficient to answer the most sophisticated and plausible versions of the objection. To the extent that naturalists have taken Quine's gesture toward engineering as the first and last word on the possibility of normative naturalism, then, those naturalists have been wrong.

I describe the basic shapes of the normativity objection and the engineering reply in Section 2. In Section 3, I sketch an account of what it could mean to call a theory "normative," and I use that account to generate seven versions of the normativity objection. Section 4 concerns what it might mean to treat normative epistemology as an engineering discipline, and I put the engineering reply up against the seven normativity objections in Section 5. In Section 6, I discuss an additional objection to naturalism that 
is not a form of the normativity objection but is closely related to it. Section 7 contains concluding remarks.

\section{The Normativity Objection and the Engineering Reply}

In "Epistemology Naturalized," Quine calls on epistemologists to stop trying to justify scientific theories and methods a priori. Instead, he thinks, they should treat knowledge (and hence science) as a natural phenomenon to be studied with the same empirical, scientific methods used to study any other natural phenomena. In that case, he says, "epistemology, or something like it, ... falls into place as a chapter of psychology" $(1969$, p. 82). It studies the ways in which a "physical human subject" transforms sensory stimulation into beliefs about "the three-dimensional external world and its history" (1969, pp. 82-3).

Advocates of the normativity objection, such as Jaegwon Kim and Wilfrid Sellars, see Quine-style naturalism as abandoning epistemology altogether. According to Kim, the empirical methods of science can tell us how we acquire our beliefs but not what justifies them. To "settle for psychology," as Quine proposes (1969, p. 75), would then be to stop trying to understand the justification of beliefs. But, in Kim's view, epistemic justification is a central component of knowledge - no theory of the latter could be complete without a theory of the former. Kim thinks justification drops out of naturalistic epistemology, but, he says (2000, pp. 305-6):

If justification drops out of epistemology, knowledge itself drops out of epistemology.... For epistemology to go out of the business of justification is for it to go out of business. 
Wilfrid Sellars' view is similar. In "Empiricism and the Philosophy of Mind," he writes:

The essential point is that in characterizing an episode or state as that of knowing, we are not giving an empirical description of that episode or state; we are placing it in the logical space of reasons, of justifying and being able to justify what one says. (1956, Sect. 36)

In Sellars' view, to understand knowledge we need a normative theory concerning the structure of the "logical space of reasons." That is, we need a theory of what counts as a good reason for what. Because Sellars thinks the space of reasons is independent of the causal-nomological order (the "realm of law"), he thinks it is beyond the reach of empirical, scientific investigation. If Sellars is right, 'scientific theory of knowledge' is oxymoronic. $^{1}$

For Sellars and Kim, theories of knowledge must be normative because knowledge is conceptually linked to the ideas of right and wrong, good and bad, by way of its conceptual connection to justified belief. Other philosophers might reach a similar conclusion by a different route. Only a true belief can be knowledge, but perhaps truth itself is conceptually connected to the idea of "right" or "good" belief or assertion. ${ }^{2}$ In that case, a theory of knowledge might need to be normative because knowledge is conceptually connected to truth, regardless of its conceptual connections to epistemic justification.

For the normativity objection, it matters less why epistemology needs to be normative than that it does. The basic shape of the objection is just this:

\footnotetext{
${ }^{1}$ See McDowell (1996) and Brandom (1994).

2 See Dummett (1959) and Wright (1992).
} 
P1 Naturalistic theories of knowledge are empirical, scientific theories.

P2 An adequate theory of knowledge must be normative (in a certain sense).

P3 Empirical, scientific theories are not (or cannot be) normative (in the sense of P2).

C Naturalistic theories of knowledge are not (or cannot be) adequate. They are either false or incomplete.

In response, naturalists might reject any of the premises. ${ }^{3}$ To keep this discussion focused on the engineering reply, however, I will assume that $\mathrm{P} 1$ and $\mathrm{P} 2$ are unobjectionable. The engineering reply's point is to provide a principled way of rejecting P3 by maintaining that empirical science can provide appropriately normative epistemological theories.

Quine sets out his version of the engineering reply in his "Reply to Morton White": Naturalization of epistemology does not jettison the normative and settle for the indiscriminate description of ongoing procedures. For me, normative epistemology is a branch of engineering. It is the technology of truth-seeking, or, in more cautiously epistemic term, prediction. Like any technology, it makes free use of whatever scientific findings may suit its purpose. It draws upon mathematics in computing standard deviation and probable error and in scouting the gambler's fallacy. It draws upon experimental psychology in exposing perceptual illusions, and upon cognitive psychology in scouting wishful thinking. It draws upon neurology and physics, in a general way, in discounting testimony from occult or parapsychological sources. There is no question here of ultimate

\footnotetext{
${ }^{3}$ Alvin Goldman might reject P1, as his naturalism consists of just the claim that epistemology "needs help" from science (Goldman, 1986; 1999). David Armstrong might reject P2; his reliabilist naturalism maintains that knowledge arises just from the lawlike connection between a state of affairs and one's belief it obtains (Armstrong, 1968).
} 
value, as in morals; it is a matter of efficacy for an ulterior end, truth or prediction. The normative here, as elsewhere in engineering, becomes descriptive when the terminal parameter is expressed. (1998, pp. 664-5)

Naturalistic epistemology, on this view, can answer engineering questions about how best to suit our cognitive means to our cognitive ends. The resulting answers will be normative theories that tell us the difference between better and worse uses of our cognitive resources, and they will be just the sort of normative theories epistemology needs. To evaluate this response to the normativity objection, though, we need to work out both the objection and the reply in considerably more detail. We need to be clearer about what it means for a theory (scientific or otherwise) to be normative, about the sense in which engineering is "normative science," and about why it is supposed to be legitimate to assimilate normative epistemology to engineering. I take up these problems in the following sections.

\section{Normative Theories and Normativity Objections}

Let us start by asking what it means to call a theory "normative." Different philosophers often have different ideas in mind when they use the word 'normative', and I do not intend the account sketched here to capture every philosophical use of the term. Rather, I intend only to shed some light on one reasonable sense of the normative/descriptive distinction as applied to theories, so as to clarify the normativity objection and the engineering reply without begging the question either way.

We can draw the normative/descriptive distinction most readily with regard to individual sentences. Some - such as 'Roses are red' - are standardly used to make 
reports, particularly concerning the properties of and relations among objects. I call such sentences descriptive. Sentences can be normative in two ways. First, a sentence might be standardly used to rate something on some scale of better or worse, good or bad, or to register one's liking or disliking, approval or disapproval of something in some respect. Such sentences are normative in virtue of being evaluative. A sentence might also be normative by being prescriptive, which is to say it is standardly used to express one's attitude of approval, disapproval, endorsement, etc. of a rule or a course of action.

These definitions depend on the idea of sentences' being used "standardly," but a sentence might sometimes or even always be used non-standardly (by actors in a play, for example). Nevertheless, there are familiar grammatical and lexical features of sentences that function to mark them as standardly used to perform various speech acts. The imperative mood, for example, is a marker of prescription, and the indicative mood often marks a sentence as descriptive. ${ }^{4}$

There is no need to suppose normativity and descriptiveness are exclusive of one another or exhaustive of all sentences. Questions strictly count as neither descriptive nor normative on this account, though their answers might. Thus we might decide to count a question as "normative," in a derived sense, just in case its answer is normative. Complex declarative sentences, such as:

Roses are red, but famine relief is good and you shouldn't insult your students. are best treated as descriptive, evaluative, and prescriptive. It may even turn out that every prescriptive sentence is necessarily evaluative, or that all evaluative sentences must also be descriptive. This is not a problem for the normative/descriptive distinction drawn

\footnotetext{
${ }^{4}$ The notion of standard use is very close to Ruth Millikan's notion of linguistic proper function (Millikan, 1984). Readers are free to interpret whatever I say about standard use in Millikanian terms, though the details of Millikan's view make no difference to the case developed in this paper.
} 
here, because any both descriptive and normative sentence has the two properties in virtue of different features. Descriptiveness and normativity are distinct even if often coinstantiated.

We can extend the normative/descriptive distinction to apply to theories as well as sentences. Accepting a theory commits one to assent to certain sentences, in the context of one's background beliefs. For example, accepting the Newtonian theory of gravitation in the context of my background beliefs would commit me to assent to:

My coffee cup exerts an attractive force on the planet Mars. When accepting a theory would commit a person to assent to a certain sentence, I call the sentence a consequence of the theory for that person. The relativization to persons can be dropped when accepting the theory would commit anyone or almost anyone to assent to the sentence. Scientific theories, such as Newton's theory of gravitation, typically have descriptive sentences among their consequences. Moral theories, on the other hand, typically have normative sentences among their consequences. I call a theory descriptive when it has some descriptive consequences, and I call a theory with normative consequences normative. There is no a priori bar to a theory's being both descriptive and normative. Such a theory would just have some descriptive as well as some normative consequences. $^{5}$

One version of the normativity objection, then, maintains that naturalistic epistemological theories are necessarily descriptive and not normative. Subtler versions identify some particular way in which epistemological theories need to be normative and

\footnotetext{
${ }^{5}$ I take the notion of commitment to a sentence as primitive. If attributions of commitments are normative, then it may be I have given a normative account of the normative/descriptive distinction as applied to theories. I am not trying to give a reductive or purely descriptive account of the distinction, though, so drawing it in normative terms is not illegitimate.
} 
contend that naturalistic theories cannot be normative in that way, even if they could be normative in some way or other. I will discuss six specific forms of normativity theories might exhibit: evaluative, prescriptive, categorical, hypothetical, well-motivated, and illmotivated normativity.

Evaluative and prescriptive normativity are straightforward. Theories with evaluative consequences (e.g., 'Greed is good') are evaluatively normative, and theories with prescriptive consequences (e.g., 'Be kind to sophomores') are prescriptively normative. Of course, a theory with both sorts of consequences would be both evaluatively and prescriptively normative.

Hypothetical and categorical normativity pertain to the sorts of evaluations or prescriptions a theory has as consequences. Some evaluative sentences, such as 'Hammers are bad airfoils', concern instrumental value - the value something has for a certain purpose or relative to a certain goal. Also, some prescriptive sentences express "hypothetical imperatives," meant to instruct only those who have adopted certain ends or goals. For a theory to be hypothetically normative is for its consequences to include evaluations or prescriptions of these kinds.

Some evaluative sentences, on the other hand, concern intrinsic value - the value something has in itself, independently of any purposes, ends, or goals. And some prescriptions express “categorical imperatives," intended to bind people without regard for their purposes, ends or goals. Theories are categorically normative when they have consequences of these kinds. It is possible, of course, for a theory to be both hypothetically and categorically normative. 
We can also make a useful distinction between well-motivated and ill-motivated hypothetical normativity. Consider the following two prescriptive sentences:

H Those who want to get the most out of their heroin should shoot up with friends.

D Those who want to get the most out of their dinner should eat with friends. Some philosophers would say that $\mathbf{D}$ is normative in an importantly different way from H. Even if it is true that shooting up with friends improves the experience of using heroin, getting the most out of one's heroin is a defective goal, a goal not worth having. In contrast, getting the most out of one's dinner is a worthwhile goal. Consequently, one might suppose $\mathbf{D}$ makes a claim on one's behavior that $\mathbf{H}$ cannot.

I call a hypothetically normative theory well-motivated if and only if its consequences include evaluations or prescriptions relativized to worthwhile ends, goals, or purposes. Hypothetically normative theories are ill-motivated if and only if they have normative consequences relativized to goals not worth having. A theory can be both welland ill-motivated by having some consequences relativized to worthwhile goals and some relativized to goals not worth having.

Now we can formulate seven versions of the normativity objection to epistemological naturalism:

Simple Normativity Objection: Naturalistic epistemological theories are inadequate because they cannot be normative at all; they cannot have normative consequences.

Evaluative Normativity Objection: Even if naturalistic epistemological theories can be normative, they are inadequate because they cannot be evaluative. 
Prescriptive Normativity Objection: Even if naturalistic epistemological

theories can be normative, they are inadequate because they cannot be prescriptive.

Hypothetical Normativity Objection: Even if naturalistic epistemological theories can be normative, they are inadequate because they cannot be hypothetically normative.

Categorical Normativity Objection: Even if naturalistic epistemological theories can be normative, they are inadequate because they cannot be categorically normative.

External Well-motivated Normativity Objection: Even if naturalistic epistemological theories can (and should) be hypothetically normative, they are inadequate because they cannot be well-motivated.

Internal Well-motivated Normativity Objection: Even if naturalistic epistemological theories can (and should) be well-motivated, they are inadequate because they are too weak to establish their own wellmotivatedness.

Kim (2000) and Sellars (1956) appear to endorse the Simple Normativity Objection. Harvey Siegel $(1990 ; 1996)$ has pressed the Categorical Normativity Objection, but his argument involves the claim that only a categorically normative theory could demonstrate its own well-motivatedness. Thus, his objection may also be a version of the Internal Well-motivated Normativity Objection. ${ }^{6}$

\footnotetext{
${ }^{6}$ Siegel argues, roughly, that an adequate hypothetically normative epistemology would have to be powerful enough to prove its own well-motivatedness, but no theory could do that without being categorically normative. Naturalistic theories, in his view, are not categorically normative and so must be inadequate. See Siegel $(1990 ; 1996)$ for the arguments, and Wrenn (2004) for objections to them.
} 


\section{Engineering and Normative Epistemology}

To see how the engineering reply stacks up against these normativity objections, we need to consider both how engineering is "normative science" and what it would mean to treat normative epistemology as an engineering discipline.

Given the version of the normative/descriptive distinction laid out above, it should be obvious that normative scientific theories are not only possible but actual. Scientific theories often commit us to normative sentences. If I accept Newtonian mechanics, for example, I am committed to counting rockets with enough fuel to reach escape velocity as better for going into outer space than rockets without enough fuel. That is not a consequence of Aristotelian mechanics, though, because there is no such thing as escape velocity in that system.

Though it is common to think of engineering as centrally concerned with problems of design - particularly the design of technological solutions to problems - we can think of engineering and applied science generally as concerned with working out the normative consequences of our scientific theories. We use them to figure out how best to pursue our goals, given that the world is the way we think it is. It is in that sense that engineering is normative science.

Consider an engineering project such as designing a bridge. The civil engineers involved will apply theories from many disciplines, including physics, meteorology, geology, economics, and more. The result of all that applied science will be a specification of the difference between good and bad bridge designs for a particular place and purpose, as well (one hopes) as the design and construction of a good bridge. 
Examples such as bridge-building show that theories applied in engineering are often both evaluatively and prescriptively normative. They are evaluatively normative because they tell us how good things are for given purposes - e.g., how good a certain kind of concrete would be for paving a bridge's driving surface. They are prescriptively normative because they tell us about how we ought to pursue our goals - e.g., what sorts of winds and loads a bridge in a given place ought to be capable of withstanding. All this normativity is clearly hypothetical; the engineers would make different evaluations and prescriptions if our goals were different. A good bridge for pedestrians is not the same as a good bridge for automobiles.

Engineering does not seem to give examples of categorical normativity in science, and that is not surprising. To be categorically normative, a theory must have consequences concerning either what we ought to do independently of our ends, goals and desires, or what has intrinsic value. When applied to practical problems, however, scientific theories work by elucidating causal connections between means and ends, not by telling us how good things are "in themselves."

Whether a hypothetically normative theory is well- or ill-motivated depends on whether the goals it tells us how to pursue are worthwhile. That is a normative question; it calls for an evaluative answer. Engineering could answer it, provided the goals' instrumental value is what matters. On the other hand, engineering looks ill-suited to tell us whether a given goal is worthwhile in itself, without regard to other ends whose worthiness is, for the moment anyway, not in question.

To assimilate normative epistemology to engineering is thus to frame its problem in a particular way. It is to treat normative epistemology as primarily concerned with 
distinguishing better from worse cognitive practices or uses of our cognitive resources, and to treat the 'better' and 'worse' as matters of conduciveness to our cognitive ends, given our best understanding of ourselves and our world. We want our cognitions to have certain results, such as belief in important truths, disbelief in dangerous falsehoods, and accurate prediction. Science tells us about how the world works and how our minds process information about it. Normative naturalized epistemology, in turn, draws on that science to evaluate the effectiveness of our cognitive means in achieving our cognitive ends.

This, I think, is what Quine has in mind when he compares normative epistemology to engineering. In Pursuit of Truth, for example, he describes how scientific theories can commit us to normative epistemological principles (1992, p. 19):

The most notable norm of naturalized epistemology actually coincides with that of traditional [empiricist] epistemology: nihil in mente quod non prius in sensu. This is a prime specimen of naturalized epistemology, for it is a finding of natural science itself, however fallible, that our information about the world comes only through the impacts on our sensory receptors. And still the point is normative, warning us against telepaths and soothsayers.

'Those who want to have true rather than false beliefs should ignore soothsayers' is a normative epistemological claim. But, as Quine points out, it is also a consequence of our best current scientific understanding of the world. Thus he thinks naturalized epistemology goes normative when it uses science to answer questions about how best to use our minds and to decide what to believe. 
The admonition against soothsayers, however, might be too trivial to convey the full flavor of normative epistemology's treatment as a branch of engineering. For a more interesting example, consider some recent research in neuroscience. Scientists studying the brain often want to locate the brain areas whose activity is responsible for subjects' performance on experimental tasks. One of their methods has been to use functional magnetic resonance imaging (fMRI), which tracks blood flow through the brain. Though fMRI has been used for some time, the legitimacy of its results was open to question for some time.

The problem was that, according to our best view of how the brain works, it processes information not by moving blood around but by passing electrical signals between neurons. fMRI measures blood flow, but it is used to make inferences about information processing. There has been good reason to think the two are correlated, but no one had been able to measure them simultaneously until fairly recently (Logothetis et al., 2001).

When scientists did measure the blood flow properties fMRI measures simultaneously with the electrical activity believed to underlie neural information processing, the results were epistemologically significant. The blood flow properties were correlated with the input and intracortical processing of a brain area, but not with its spiking output (Logothetis et al., 2001, p. 150). The results thus provided more than just a vindication of fMRI as a means of localizing brain activity. They also gave guidance on the future application of fMRI methods. They showed that fMRI provides a good way to locate brain areas that are receiving input or performing processing, but it does not provide a good way to locate areas producing output signals. 
Such results are not unusual in neuroscience or in science generally. They typify a scientific genre concerned with finding correlations between various phenomena and measures of them, as well as correlations among measures. Such work amounts to hard core, normative naturalistic epistemology; it gives scientific answers to questions about how we ought to find out about things. I now turn to the question whether this is enough to answer the normativity objections.

\section{The Engineering Reply Appraised}

The engineering reply clearly succeeds against at least four versions of the normativity objection. Among the consequences of our best scientific understanding of the world are these:

S Those who want to have true beliefs about the future should not rely on soothsayers.

F fMRI studies are a good way to localize the intracortical processing associated with an experimental task.

$\mathbf{S}$ and $\mathbf{F}$ are normative; the former is a prescription and the latter is an evaluation.

Immediately, then, the Simple, Evaluative, and Prescriptive Normativity Objections can be seen to fail. Both $\mathbf{S}$ and $\mathbf{F}$ are also hypothetically normative; $\mathbf{S}$ purports to bind only those who want to have true beliefs about the future, and $\mathbf{F}$ assesses the value of fMRI only as a means to localizing intracortical processing. They are enough, then, to show that the Hypothetical Normativity Objection fails as well.

It is no surprise that the engineering reply handles these objections. The Simple Normativity Objection is just too logically strong to be plausible; it claims naturalistic 
epistemology cannot be normative at all. The Evaluative and Prescriptive Normativity Objections look weaker, but it is plausible that evaluative and prescriptive consequences come as a package deal. If they do (that is, if evaluative theories are always prescriptive and vice versa), then those objections are actually equivalent to the Simple Normativity Objection.

I do not know of anyone who has seriously pressed the Hypothetical Normativity Objection. This is probably because philosophers who are sensitive to the difference between hypothetical and categorical normativity easily see that hypothetical normativity is within empirical science's reach. Such normativity is just a matter of causal connections between means and ends, and causal connections are science's stock in trade. Thus it is also unsurprising that naturalistic epistemology could give us hypothetical evaluations and prescriptions.

One might object here that it is wrong to assume the means/end relation is purely causal, because something's status as a means or end depends on the attitudes of an agent. ${ }^{7}$ Such an objection would turn on a confusion, however. The point here is not that science can be hypothetically normative because the means/end relation is purely causal. The point is that purely causal factors account for how good or bad a means is relative to a given end, regardless of whether anyone actually employs that means or adopts that end. Hammers make bad airfoils for purely causal reasons, and they make bad airfoils even if no one ever actually tries to use a hammer to manipulate surrounding air currents and generate lift. Engineering and applied science are in the business of answering counterfactual questions about how successful one would be if one were to pursue certain

\footnotetext{
${ }^{7}$ Thanks to an anonymous referee for drawing my attention to this objection.
} 
ends by certain possible means. Those questions are answerable on purely causal grounds, even if the means/end relation itself includes non-causal factors.

Nevertheless, there are reasons one might have thought the engineering reply could not work against even these four unsophisticated normativity objections. In particular, one might think normative epistemology modeled on engineering would necessarily run afoul of G. E. Moore's so-called "naturalistic fallacy." Moore argues that goodness cannot be identified with any "natural" (i.e., causal or non-evaluative) property, for it is always an open question whether any such property is good and never an open question whether good is good or such a property is itself (Moore, 1922, §§10-14). When we model normative epistemology on engineering, however, we identify the epistemic good with a natural property, namely the achievement or promotion of epistemic ends. Surely, one might think, that is a problem for naturalism.

It is not; Moore's reasoning simply does not apply in the present case. He is concerned with a certain kind of goodness - intrinsic moral goodness. Even if it is a mistake to identify that sort of goodness with a natural property, it is far less clearly wrong to identify the epistemic good with the achievement or promotion of epistemic ends. It might be an open question whether achieving or promoting epistemic ends is morally good, or intrinsically good, or just plain good, but this question:

Is achieving or promoting epistemic ends epistemically good? is not open at all. ${ }^{8}$

\footnotetext{
${ }^{8}$ It might be an open question, though, whether achieving or promoting our cognitive ends is epistemically good. That is because our cognitive ends might include such things as having an internally consistent set of desires, which are clearly outside the scope of epistemology. The lesson here is just that normative naturalistic epistemology, qua epistemology, is concerned not with the promotion of all our cognitive but only our characteristically epistemic cognitive ends.
} 
The serious challenges to naturalism thus begin with the Categorical Normativity Objection ("CNO" henceforth). It says that epistemology needs more than the hypothetical normativity that derives from the causal ties between our cognitive means and ends. According to the $\mathrm{CNO}$, epistemology needs categorical normativity; it needs consequences concerning intrinsic value or our intellectual obligations independent of our cognitive goals. These are just the sort of normative consequences empirical theories lack, and there is no reason to think naturalistic epistemology can deliver them.

A naturalist might try to respond by showing how naturalistic epistemology, or maybe just science in general, can be categorically normative after all. I doubt this strategy would succeed, but even if it did it would go well beyond the engineering reply. We do not have examples of categorically normative engineering, so the analogy between normative epistemology and engineering gives us no reason to expect categorically normative consequences from naturalistic epistemology.

Some avowed naturalists have faced up to the $\mathrm{CNO}$ by arguing against its claim that epistemology needs to be categorically normative. Larry Laudan $(1984 ; 1987 ; 1990)$ argues that all the normative questions in epistemology and the philosophy of science are hypothetically normative. Alvin Goldman (1986) criticizes the idea that there are categorically normative epistemological prescriptions. And Hilary Kornblith (1993) argues that the ultimate source of epistemic value is the instrumental, rather than intrinsic, value of true belief.

It is beside my point whether these efforts succeed, and to some extent it is even beside my point whether epistemology needs to be categorically normative. I just want to emphasize that the engineering reply does not show that epistemology can do without 
categorical normativity. It shows that certain parts of normative epistemology can be treated as the engineering side of naturalistic epistemology. It does not show that those are all the parts of normative epistemology, or even that they are the most important parts.

The point may seem obvious, but Quine himself seems to overlook it. When he gives his version of the engineering reply at the close of "Reply to Morton White," he appears to make two claims. First, he says hypothetically normative naturalistic epistemology is possible. Second, he says hypothetical normativity is all epistemology needs. But the only reason Quine seems to have for the second claim is the fact that hypothetical normativity is all naturalistic epistemology delivers. As Quine says of a different argument elsewhere, ${ }^{9}$ this defense of naturalism is not flatly circular, but it does have the form of a closed curve in space.

The engineering reply fares a little bit better against the External Well-motivated Normativity Objection (EWNO). According to that objection, epistemology's hypothetically normative consequences should be relative to worthwhile ends, that is, ends that are worth pursuing. But, says the EWNO, naturalistic epistemology cannot meet this demand; the ends relative to which it makes evaluations and prescriptions are not worthwhile. Some philosophers otherwise sympathetic to naturalistic epistemology have rejected it on just these grounds: Naturalistic epistemology might tell us how best to pursue such ends as truth or accurate prediction, but those ends are not worth pursuing. ${ }^{10}$ If the objection is right, then naturalistic epistemology gives us prescriptions and evaluations we lack good reasons to care about.

\footnotetext{
${ }^{9}$ Quine (1980, p. 30).

${ }^{10}$ See Rorty (1979) and Stich (1990).
} 
The best course for naturalists would be to defend the value of our epistemic ends, such as truth or accurate prediction or whatever they turn out to be. Here there is considerable room to maneuver. The EWNO demands only that these ends actually be worthwhile, and the question of their worth might well be outside epistemology. If it is, then epistemological naturalists are not automatically required to approach it as a question for empirical science. Maybe our epistemic ends are worthwhile on a priori moral or aesthetic grounds.

If naturalists treat the question of epistemic ends' worth as outside epistemology, though, the engineering reply is obviously not much help to them. The fact that science might be able to tell us about how best to make accurate predictions goes nowhere in telling us whether making accurate predictions is worth trying to do.

Nevertheless, our epistemic ends might be worth pursuing on instrumental grounds. Believing what is true rather than false might be so instrumentally valuable we all have an interest in doing it. ${ }^{11}$ Or, pursuing the truth might have enough instrumental value of its own to make it a worthwhile activity. ${ }^{12}$ In such cases, naturalists could work at least in the spirit of the engineering reply and use science to investigate the instrumental worth of our epistemic goals. The category of "good epistemic goals" would then be an engineering category, because the relevant kind of goodness would be something in the neighborhood of optimality with respect to the rest of what we want.

The Internal Well-motivated Normativity Objection (IWNO) closes the EWNO's loophole. It maintains that the value of our epistemic goals must be established from

\footnotetext{
${ }^{11}$ See Kornblith (1993).

${ }^{12}$ See Wrenn (2001).
} 
within epistemology. Not only must an adequate epistemology give guidance for the pursuit of worthy epistemic goals, it must explain why they are worthy.

In light of the naturalist's options against the EWNO, it is unlikely that a proponent of IWNO would settle for an engineer's explanation of our epistemic goals' instrumental value. The insistence that epistemology account for the value of such goals as believing truths rather than falsehoods or making accurate predictions is the insistence that epistemology account for that value completely. That means either showing the goals are intrinsically valuable or showing they are instrumentally valuable with respect to other, intrinsically valuable goals, whose intrinsic value the theory also explains. Anything less would be an incomplete account of our epistemic goals' value; it would be less than everything needed to show that our epistemic goals are worth pursuing or caring about.

The IWNO, then, is really just an elaboration of the Categorical Normativity Objection. It contends that naturalistic epistemology needs to be not just categorically normative, but categorically normative in the right way to explain our epistemic ends' value fully. It might be wrong to place this demand on epistemology. Maybe it is legitimate for epistemology to take the value of our epistemic goals for granted, just as bridge-designers legitimately presuppose that building bridges is at least sometimes worth doing. Or maybe intrinsic value is the exclusive province of ethics, and so it is unfair of the IWNO to demand an explanation of it from epistemology. In any case, the point here is the same as with the CNO: If the objection fails, it fails for reasons the engineering reply does not reveal. The fact that naturalistic epistemology can give hypothetically normative guidance on the conduct of our cognitive lives is just not enough to show that our epistemic ends are worth pursuing or caring about. 


\section{One More Normativity Objection?}

Another objection lurks in the same general neighborhood as those surveyed above, especially the IWNO. One might hold that knowledge is "intrinsically" or "essentially" normative in the following sense: It is part of the essence of knowledge that it is desirable, or good, or to be pursued, or the "norm of belief" (i.e., what beliefs qua beliefs ought to be like). Such a view would be particularly plausible to someone who thinks it is part of the concept of knowledge that knowledge is desirable (or good or to be pursued or ...). Given this view, one might also claim that epistemology modeled on engineering is committed to treating knowledge as "extrinsically" normative - i.e., desirable (or good or ...) not essentially but only in virtue of its contingent causal relations with our cognitive ends. Thus naturalistic epistemology would incorrectly treat 'Knowledge is good' as contingently true when in fact it is necessary.

This is not the same as the Categorical Normativity Objection; it is not the objection that naturalism cannot explain knowledge's intrinsic value. One could hold that knowledge's value is wholly instrumental while also maintaining that knowledge has its value essentially. An advocate of that view might object that naturalism treats knowledge's value as accidental rather than essential. Similar objections might also be raised concerning the value of epistemic justification or even truth. ${ }^{13}$

The versions of the normativity objection discussed above all claim that naturalistic epistemology is too weak to deliver the sort of normative results we want from epistemology. Unlike those objections, this one attributes a positive thesis - that

\footnotetext{
${ }^{13}$ See Horwich (1998) for more on intrinsic and extrinsic normativity, including good reasons to think the normativity of meaning and related phenomena is extrinsic (Chapter 8).
} 
knowledge (etc.) is only contingently valuable - to naturalism, and it maintains that that thesis is false. For symmetry's sake, however, let us call this the "Modal Normativity Objection" or "MNO."

The MNO stands or falls with the claims (a) that naturalism is committed to knowledge's merely contingent or accidental value and (b) that knowledge is essentially valuable. There is plenty of room to doubt both claims, especially the first. Surely there is room for naturalists who take each of these views:

A 'Knowledge' is a natural kind term rigidly designating the very same state in all worlds, regardless of that state's value in a given world.

B 'Knowledge' is a functional term that designates whatever sort of true belief is most valuable in a given world.

Call those who take the first view A-naturalists and those who take the second view Bnaturalists. There might even be $\mathbf{C}$-naturalists, who hold that 'knowledge' is ambiguous between what A-naturalists say and what B-naturalists say. Only A-naturalism makes knowledge "extrinsically normative" or contingently valuable. B-naturalism clearly lacks the commitment the MNO attributes to naturalism.

As before, though, we find that the engineering reply does not help the naturalist facing the Modal Normativity Objection. The engineering reply shows that we can look to science for guidance about how best to pursue our cognitive ends. That sheds no light on the question whether knowledge is essentially or only accidentally desirable (or good or ...). If the MNO fails, it fails for reasons other than what the engineering reply reveals.

\section{Conclusion}


Quine probably had the Simple Normativity Objection in mind when he proposed the engineering reply. The comparison of normative epistemology to engineering is enough to answer that objection, as well as the similarly unsophisticated Evaluative, Prescriptive, and Hypothetical Normativity Objections.

Nevertheless, the engineering reply cannot answer the more sophisticated versions of the normativity objection. Those versions either demand categorical normativity of epistemology, or they draw attention to the problem of establishing the worth of our epistemic ends. Even if the latter is not, strictly speaking, an epistemological problem, it is one in which epistemologists should take an interest. Nor does the reply have any bearing on the Modal Normativity Objection. Far from being the last word on the possibility of normative naturalistic epistemology, the engineering reply misses the point of the most sophisticated and philosophically interesting versions of the normativity objection.

Those versions of the objection are not more sophisticated merely in virtue of embodying more stringent standards of adequacy for epistemological theories. More to the point, they are more plausible than their simpler cousins, and they may provide more charitable interpretations even of Sellars and Kim's objections, which look to be versions of the Simple Normativity Objection on first inspection. The plausible objection to naturalism, and the one that naturalism needs to answer, is not that science cannot be normative. It is that naturalistic epistemology either cannot give us normative guidance we should care about or cannot show us its guidance is worth caring about at all.

If the engineering reply has a flaw, then, it is hubris. The reply establishes the hypothetical normativity of naturalistic epistemology, but it would be a mistake to think 
(as Quine seems to) that it thereby answers the demands of serious normativity objections. Answering the most sophisticated, plausible versions of the normativity objection will require more than the engineering reply provides.

\section{References}

Armstrong, D. M. 1968. A Materialist Theory of the Mind. Rev. ed. London: Routledge. Brandom, R. 1994. Making it Explicit. Cambridge, MA: Harvard U P.

Dummett, M. 1959. “Truth.” Proceedings of the Aristotelian Society. 59: 141-62.

Goldman, A. 1986. Epistemology and Cognition. Cambridge, MA: Harvard U P.

----. 1999. “A Priori Warrant and Naturalized Epistemology.” In: Tomberlin, J. E., ed., Philosophical Perspectives 13: Epistemology. Cambridge: Blackwell.

Horwich, P. 1998. Meaning. Oxford: Clarendon.

Kim, J. 2000. “What is 'Naturalized Epistemology'?” In: Sosa, E. and Kim, J., eds., Epistemology: An Anthology. pp. 301-13. Malden, MA: Blackwell.

Kornblith, H. 1993. “Epistemic Normativity.” Synthese. 94: 357-76.

Logothetis, N., Pauls, J., Augath, M., Trinath, T., Oeltermann, A. 2001.

"Neurophysiological Investigation of the Basis of the fMRI Signal." Nature. 412 (12 July 2001): $150-157$.

McDowell, J. 1996. Mind and World. Cambridge, MA: Harvard U P.

Millikan, R. 1984. Language, Thought, and Other Biological Categories. Cambridge, MA: MIT Press.

Moore, G. E. 1922. Principia Ethica. Cambridge, UK: Cambridge U P. 
Quine, W. V. 1969. "Epistemology Naturalized.” In: Ontological Relativity and Other Essays. pp. 69-90. New York: Columbia U P.

----. 1980. “Two dogmas of empiricism.” In: From a Logical Point of View. 2d ed. pp. 20-46. Cambridge, MA: Harvard U P.

-----. 1992. Pursuit of Truth. Rev. ed. Cambridge, MA: Harvard U P.

-----. 1998. "Reply to Morton White.” In: Hahn, L. and Schilpp, P., eds. The Philosophy

of W. V. Quine. 2d ed. pp. 663-5. Chicago: Open Court.

Rorty, R. 1979. Philosophy and the Mirror of Nature. Princeton, NJ: Princeton U P.

Sellars, W. 1956. "Empiricism and the Philosophy of Mind." In: Feigl, H. and Scriven, M., eds.

Siegel, H. 1990. “Laudan's Normative Naturalism.” Studies in History and Philosophy of Science. 21 (2): 295-313.

-----. 1996. "Naturalism, Instrumental Rationality, and the Normativity of Epistemology." Protosociology. 8/9: 97-110.

Stich, S. 1990. The Fragmentation of Reason. Cambridge, MA: MIT Press.

Wrenn, C. 2001. Truth and the Normativity of Naturalistic Epistemology. Doctoral Dissertation. Washington University in St. Louis.

-----. 2004. "Hypothetical and Categorical Epistemic Normativity." The Southern Journal of Philosophy. Vol. 42 no. 2 (Summer 2004), pp. 273-290.

Wright, C. 1992. Truth and Objectivity. Cambridge, MA: Harvard U P. 